\title{
I mpactos do livro de uma mulher vítima na vivência de violência conjugal de outras mulheres
}

\section{Impacts of the book of a marital violence victim in the experience of other women}

\section{Los impactos del libro de una víctima de violencia conyugal en la experiencia de otras mujeres}

\author{
Fabrício Lemos Guimarães* \\ Universidade de Brasília - UnB, Brasília, Distrito Federal, Brasil \\ Gláucia Ribeiro Starling Diniz** \\ Universidade de Brasília - UnB, Brasília, Distrito Federal, Brasil
}

\begin{abstract}
RESUMO
Esta pesquisa qualitativa teve como objetivo compreender os impactos da história de uma personagem/mulher vítima na vivência de violência conjugal de outras mulheres, por meio da leitura, resposta a questionário e reflexão grupal sobre o livro "Mas ele diz que me ama: graphic novel de uma relação violenta". As participantes foram 20 mulheres que estavam em acompanhamento psicossocial encaminhadas pela justiça. A estratégia metodológica utilizada facilitou um contexto de reflexão sobre comparações entre as histórias pessoais das participantes e a da personagem do livro; favoreceu a percepção de suas próprias anestesias relacionais; contribuiu para a conscientização e a nomeação da violência vivenciada. Essa proposta de pesquisa-intervenção mostrou seu potencial e utilidade como método de pesquisa e como modelo de intervenção clínica.
\end{abstract}

Palavras-chave: violência, gênero, anestesia relacional, intervenção.

\begin{abstract}
This qualitative research was aimed at understanding the impacts of history of a marital violence victim in the experience of other women, through reading, answer the questionnaire and group reflection on the book "Dragon slippers: This is what an abusive relationship looks like". The participants were twenty women who were referred for Justice to psychosocial care. The methodological approach created a suitable context for reflection about comparisons between the personal stories of participants and the character of the book; has favored the perception of their own relational anesthetic; contributed to awareness and naming of the violence experienced. This proposed research intervention confirmed its potential and utility as a research procedure and as an important clinical resource.
\end{abstract}

Keywords: violence, gender, relational anesthetic, interventions. 


\begin{abstract}
RESUMEN
Esta investigación cualitativa tuvo como objetivo comprender el impacto de la historia de un personaje / una mujer víctima de la violencia conyugal en la experiencia de otras mujeres, a través de la lectura, a responder el cuestionario y el grupo de reflexión sobre el libro "Pero él dice que me ama, novela gráfica de una relación violenta". Las participantes fueron 20 mujeres que estaban en el apoyo psicosocial enviado por los tribunales. El enfoque metodológico facilitó un contexto de reflexión sobre las comparaciones entre las historias personales de las participantes y la personaje del libro; favorecido la percepción de su propia anestesia relacional; contribuido a la toma de conciencia y el nombramiento de violencia que se vive. Esta investigación-intervención propuesta ha demostrado su potencial y utilidad como método de investigación y como modelo de intervención clínica.
\end{abstract}

Palabras-clave: violencia, género, anestesia relacionales, intervención.

Quando conheci Brian, me apaixonei profundamente. Imaginei que viveríamos um romance de contos de fadas. E vivemos.... Por algum tempo.... Até que as coisas começaram a mudar (Penfold, 2005/2006).

Trabalhar com homens, mulheres e casais em situação de violência constitui um enorme desafio. A dificuldade que homens e mulheres têm de perceber e nomear a violência em sua dinâmica relacional sempre chamou nossa atenção como clínicos-pesquisadores. As narrativas indicavam que as pessoas envolvidas não conseguiam enxergar as dimensões da violência nem tampouco nomeá-las. Há uma tendência de negar, minimizar e silenciar a violência (Hamilton, Koehler \& Lösel, 2013; Medeiros, 2015; Moore, 2015; Santos \& Moré, 2011), o que gera um desafio clínico e de pesquisa que não podia ser ignorado.

O contato com o livro "Mas ele diz que me ama" (Penfold, 2006) foi um passo importante para lidar com o desafio acima exposto. Inicialmente, o livro foi utilizado em alguns atendimentos individuais às mulheres que negavam a gravidade de sua experiência. O livro era emprestado à mulher com o pedido de que ela fizesse a leitura durante a semana. Ao retornar para o atendimento seguinte ficava evidente que a leitura produzia um forte impacto nas mulheres vítimas de violência - elas passavam da negação para a afirmação da violência.

A história da personagem incitava reflexões e provocava uma mudança na narrativa das mulheres. O drama de outra mulher permitia a elas a identificação e, consequentemente, o falar sobre sua própria história conjugal violenta. Assim, surgiu a ideia de utilizar esse livro nos atendimentos grupais e construir uma metodologia mais consistente para a sua aplicação. Essa pesquisa relata parte dessa experiência de utilização do livro como material clínico. 
É importante fazer uma breve apresentação da história contada no livro à luz de alguns referenciais teóricos adotados nessa pesquisa para contextualizar a sua utilização. Entendemos que a compreensão das anestesias relacionais (Ravazzola, 1997, 1998, 2007) e dos ciclos de violência (Walker, 1979, 1999; Walker, Duros \& Tome, 2007) constitui ferramenta necessária para ajudar no entendimento da relação conjugal violenta, em especial de como casais (inclusive o do livro) permanecem por tanto tempo em uma relação tão adversa.

O livro relata a história da relação conjugal violenta vivida pela autora/personagem e que perdurou por 10 anos. É protagonizado por Rosalind (Roz) - 35 anos, solteira e empresária - e Brian - viúvo e pai de quatro filhos. A narrativa mostra como Roz passou de uma mulher forte, decidida, feliz e bem-sucedida profissionalmente a esposa violentada e maltratada (Penfold, 2006). Mostra desde a negação da violência ao processo gradativo de empoderamento, até a ruptura do relacionamento e a retomada da vida da personagem após a separação. Segundo o site oficial da autora (http://www.dragonslippers.com/), o livro é sucesso editorial. Foi lançado originalmente no Canadá, traduzido para nove idiomas e publicado em 11 países, inclusive no Brasil (Guimarães, Silva \& Maciel, 2007; Penfold, 2006).

As anestesias relacionais são pensamentos, sentimentos e ações que fazem com que casais não percebam ou minimizem a relação conjugal ou familiar violenta (Ravazzola, 1997, 2007). As anestesias dos personagens - Roz e Brian - se aperfeiçoaram no decorrer da história e ficaram cada vez mais fortes à medida que a violência aumentava de intensidade e frequência. Roz iniciou com uma leve confusão no primeiro episódio de agressão até chegar, anos depois, à constatação de que estava totalmente fragilizada e despersonalizada. Essa confusão é exemplificada no relato de Roz: "não sobrou nada de mim" (Penfold, 2006, p.169). Brian ficou cada vez mais controlador e violento. Ele não enxergava os malefícios de seus comportamentos agressivos para a parceira e as crianças. Casais em situação de violência tendem a vivenciar processo semelhante (Diniz, 2011; Macedo, 2013; Pondaag, 2009).

Várias anestesias são apresentadas no livro. Elas sustentam a anestesia principal - acreditar que o amor está acima de tudo - em torno da qual o livro foi nomeado: "mas ele diz que me ama". As anestesias dificultam também a conscientização da gravidade das consequências das agressões para todos os envolvidos (Macedo, 2013; Ravazzola, 1997).

O livro mostrou a ocorrência de diversos Ciclos de Violência na dinâmica do casal (Walker, 1979, 1999). A história iniciou com a primeira Lua de Mel: Roz ficou encantada com o estilo de Brian. Ele se apresentou como impulsivo, romântico e sedutor. As outras fases do ciclo de violência foram se instalando de forma sutil. A fase 
denominada Construção da Tensão surgiu a partir de diversos atos agressivos de Brian e da anulação de Roz, mas eles não percebiam a dinâmica vivida como violenta. Brian fez a proposição de o casal viver como uma só pessoa: impôs que Roz abrisse mão de seus próprios sonhos; desqualificou os planos profissionais dela; denegriu a imagem da mãe de Roz e a isolou do convívio de suas amigas. Nessa fase do ciclo houve redução significativa da rede social e familiar de Roz.

A tensão foi aumentando de intensidade até ocorrer a primeira agressão física, que configurou a primeira experiência da fase intitulada como Tensão Máxima. Após vivenciar o primeiro ciclo de violência completo, Roz começou a ter dúvidas quanto a seu relacionamento e a experienciar confusões sobre seus próprios sentimentos. O retorno à fase de Lua de Mel fez a personagem ignorar os episódios violentos e investir novamente em sua relação. Roz passou a morar na casa de Brian e a tratar os filhos dele como seus (Guimarães et al., 2007).

As pesquisas de Walker (1979, 1999) e Walker, Duros, \& Tome (2007) revelaram que o ciclo de violência é uma dinâmica comum a casais em situação de violência e sua repetição tende a provocar o desgaste gradativo da relação. Entretanto, a autora aponta que o retorno à fase de Lua de Mel constitui um dos fatores que contribuem para a permanência na relação.

O livro mostra como o resgate da rede social e familiar de Roz, principalmente da mãe e de suas amigas, associado à ajuda profissional foram determinantes para romper o ciclo de violência. Tudo isso fortaleceu Roz na luta contra o parceiro e contra si mesma no sentido de quebrar suas próprias anestesias (Ravazzola, 1997, 1998; Walker, 1999). O livro confirma a necessidade de intervenções, tanto da rede social quanto institucional no processo de empoderamento de mulheres para lidarem e/ou saírem de situações de violência (Angelim, 2009; Angelim \& Diniz, 2010; Guimarães et al., 2007; Yamamoto \& Colares, 2015).

A partir de uma perspectiva sistêmica e clínica marcada por um olhar de gênero, esse trabalho é um resumo de pesquisa de mestrado que teve como objetivo verificar o impacto da história de uma mulher na vivência de violência conjugal de outras mulheres, por meio da leitura e reflexão em grupo do livro "Mas ele diz que me ama" (Penfold, 2006). Os objetivos específicos foram: 1) Identificar os sentimentos despertados nas mulheres pela leitura do livro; 2) Compreender os elementos que as mulheres identificaram como semelhantes ou diferentes ao compararem suas histórias pessoais com a da autora do livro; 3) Identificar as anestesias relacionais que mais influenciaram a permanência no relacionamento e/ou a dificuldade em pedir ajuda; 4) Conhecer como as mulheres nomeavam e percebiam a sua própria 
história, a partir da utilização do título do livro como elemento estimulador.

\section{Método}

Adotamos uma estratégia de pesquisa qualitativa a partir do uso de um estímulo indutor de reflexões, no caso o livro "Mas ele diz que me ama" (Penfold, 2006). Fomos buscar na história de uma mulher, escrita de forma criativa, o elemento potencializador de reflexões sobre a experiência de violência conjugal de outras mulheres. A dimensão inovadora dessa estratégia justifica o caráter exploratório da pesquisa (Seidl de Moura \& Ferreira, 2005).

\section{Participantes}

As participantes da pesquisa foram 20 mulheres em situação de violência conjugal que estavam em acompanhamento psicossocial em um dos nove Núcleos de Atendimento às Famílias e Autores de Violência Doméstica - NAFAVD da Secretaria de Estado da Mulher SEM do Governo do Distrito Federal - Brasil. Esse acompanhamento psicossocial é estruturado em várias etapas. A primeira é composta por uma sequência de atendimentos individuais/familiares seguida de encaminhamento para grupos de homens e de mulheres. A etapa grupal tem duração média de quatro meses.

As mulheres faziam parte de dois grupos: dez participavam de um grupo que estava no início do processo e dez participavam de um grupo que estava chegando ao fim. O objetivo de trabalhar com mulheres em momentos distintos do processo foi investigar semelhanças e diferenças nas percepções e reflexões das mulheres de cada grupo no intuito de trazer uma visão mais ampla de dimensões do fenômeno estudado.

Instrumentos

Os instrumentos utilizados nessa pesquisa foram o livro "Mas ele diz que me ama" (Penfold, 2006); um questionário criado pelos pesquisadores e o Formulário de Acolhimento de Mulheres do NAFAVD. Os instrumentos são descritos brevemente a seguir.

Livro "Mas ele diz que me ama"

A escolha metodológica pela utilização do livro "Mas ele diz que me ama" (Penfold, 2006) como instrumento eliciador de reflexões se deveu ao fato dele ter sido escrito e ilustrado na forma de história em quadrinhos. É de fácil compreensão e não se trata de um livro 
teórico, acadêmico. Ao mesmo tempo em que a história é narrada, a autora estabelece um diálogo com o(a) leitor(a), o que facilita uma identificação desse(a) leitor(a) com a personagem. O livro foi testado em atendimentos individuais. Uma vez constatado seu potencial clínico, se tornou o principal instrumento dessa pesquisa.

\section{Questionário sobre o Livro "Mas Ele Diz que me Ama"}

O questionário foi construído de acordo com os objetivos da pesquisa e era composto pelas seguintes questões: 1. Descreva qual foi o(s) sentimento(s) que você teve ao ler este livro. 2. O que tem em comum na história do seu relacionamento e na história da personagem do livro - Roz? 3. O que tem de diferente em sua história? 4. $\mathrm{Na}$ folha em anexo, marque com um " $X$ " nos pensamentos/sentimentos da Roz que são parecidos com os pensamentos que você teve. 5. Escolha 3 desses pensamentos que mais influenciaram em sua história. 6. Além dos pensamentos apresentados pela Roz, você teve outros que te impediram de pedir ajuda, de quebrar o ciclo de violência ou de sair do relacionamento? 7. A Roz resumiu a história dela com o título: "Mas ele diz que me ama...". Qual seria o título da sua história? 8. Inspirada em sua história, complete o título do livro: Mas ele diz que me ama...

A questão quatro foi acompanhada por uma folha em anexo contendo uma cópia das duas contracapas do livro, que contêm as 35 anestesias apresentadas pela autora em forma de quadrinhos - que apresentam o rosto, expressões, pensamentos e sentimentos da personagem principal. Esses pensamentos e sentimentos refletem as anestesias de Roz, que dificultavam a sua saída do relacionamento e/ou pedido de ajuda (Ravazzola, 1997, 1998, 2007). A utilização das cópias das contracapas na pesquisa foi autorizada pela editora do livro no Brasil.

Essas anestesias estão listadas abaixo (os grifos são da autora Penfold, 2006): Talvez ele melhore...; Eu não deveria perdoar?; Será que outro homem seria melhor?; Sei que ele não fez de propósito...; Quem acreditaria em mim?; Ele pediu desculpas...; Não deveria ser paciente?; Quem disse que a vida é fácil?; Ele só tomou umas cervejas...; Não está bêbado nem nada...; Não bebe durante o dia.; É um grande homem...; $E$ às vezes até bebe menos...; Nunca aprenderei a dizer a coisa certa?; Onde foi que eu errei?; Como posso abandonar as crianças?; Pode ser um transtorno de humor.; Talvez eu deva falar menos...; Talvez eu não seja sensível; Poderia ser muito pior...; Será que é mesmo tão ruim?; Talvez só esteja estressado; Ele jura que não vai acontecer de novo...; E se eu for o problema?; Sei que ele me ama...; Será alcoolismo?; E vinho no jantar; Não é uma pessoa má; Poxa, ele tem um bom emprego...; Então aguenta mais que os outros...; 
Então não tem como ser alcoólatra...; Se eu fosse mais compreensiva...; Se eu me esforçar mais...; Talvez eu seja sensível demais...; A culpa não é dele.

Formulário de Acolhimento de Mulheres

Esse formulário é preenchido por todas as mulheres encaminhadas ao NAFAVD. Foi incluído como instrumento da pesquisa para fornecer dados demográficos das participantes.

\section{Estratégias de Coleta e de Análise de Dados}

Todas as mulheres participaram de entrevista individual, em que foram convidadas a participar da pesquisa. A coleta de dados fez parte do processo grupal e foi realizada em dois encontros para cada grupo de mulheres - do início e do final do acompanhamento psicossocial. As atividades desenvolvidas foram: 10 encontro: 1) Leitura e assinatura do Termo de Consentimento Livre e Esclarecido; 2) Empréstimo de um exemplar do livro (Penfold, 2006); 3) Entrega do questionário sobre o livro e pedido de preenchimento individual do mesmo durante a semana. 20 encontro: 1) Recolhimento do questionário preenchido; 2) Discussão grupal sobre o livro e as perguntas do questionário.

O intervalo de tempo entre o primeiro e o segundo encontro em cada grupo foi de uma semana. Os encontros foram facilitados pelo mestrando, auxiliado por duas estagiárias. O segundo encontro teve duração aproximada de uma hora e meia para cada grupo. 0 procedimento de condução desse segundo encontro foi padrão para os dois grupos: a dinâmica foi iniciada a partir de uma pergunta sobre a impressão geral das mulheres ao ler o livro, seguida pela reflexão grupal de cada tópico do questionário.

Um nome foi atribuído a cada grupo ao final da pesquisa. Esse nome foi escolhido dentre os títulos atribuídos pelas participantes para suas histórias, em resposta ao item oito do questionário. A ideia foi selecionar um nome que representasse melhor a postura de cada grupo em relação ao processo de reflexão. O Grupo Saindo do Cativeiro - GSC tinha como participantes as mulheres que estavam chegando ao fim do acompanhamento psicossocial. Essas mulheres já estavam sendo capazes de re-significar suas histórias e de tomar iniciativas para reconstruir as suas vidas. O Grupo Um Dia Serei Feliz - GSF nomeia o processo das participantes que estavam no início da intervenção. O nome representa a esperança de mudança de sua realidade e do fim do sofrimento vivenciado por conta da violência conjugal.

A natureza qualitativa da pesquisa nos levou a privilegiar a análise de conteúdo das respostas aos questionários preenchidos pelas mulheres 
participantes. O procedimento para a análise de conteúdo utilizado nessa pesquisa foi a criação de categorias a partir da leitura flutuante e exaustiva das respostas das participantes (Seidl de Moura \& Ferreira, 2005).

Foi estabelecido procedimento para permitir a categorização das anestesias relacionais (Ravazzola, 1997, 1998, 2007). O mestrando criou categorias a partir do conteúdo trazido pelas participantes com base na revisão de literatura. Em reunião de equipe, a orientadora e outras três mestrandas atuaram como juízas. As anestesias foram lidas e cada membro da equipe alocou independentemente cada anestesia na categoria que julgou pertinente. Em um segundo momento, foi verificado o grau de concordância/discordância entre as juízas.

O projeto de pesquisa foi submetido e aprovado pelo Comitê de Ética e Pesquisa do Instituto de Ciências Humanas $(\mathrm{IH})$ da Universidade de Brasília (UnB).

\section{Resultados e Discussão: da História do Livro às Histórias Reais}

As mulheres participantes mostraram boa adesão ao procedimento utilizado neste estudo. No Grupo Saindo do Cativeiro - GSC todas as mulheres compareceram ao segundo encontro, leram o livro e responderam o instrumento. No Grupo Um Dia Serei Feliz - GSF apenas uma participante não compareceu neste encontro. No início do segundo encontro grupal, o pesquisador perguntou às participantes o que elas acharam da história de Roz. Essa reflexão foi seguida da discussão sobre as respostas dadas a cada pergunta do questionário.

Sentimentos Oriundos da Leitura do Livro

A primeira pergunta do questionário buscou averiguar os sentimentos das mulheres a respeito da leitura do livro "Mas ele diz que me ama" (Penfold, 2006). A partir da análise de conteúdo, os sentimentos descritos pelas mulheres compuseram três categorias: 1. Mal estar diante da situação de vitimização de Roz; 2. Comparação da história da personagem com a própria história; 3 . Identificação total com a personagem.

Algumas participantes demonstram sentimentos de mal estar diante da violência conjugal revelado pelas seguintes descrições: "triste por ver ele enganando o tempo todo e ela não querer enxergar o que ele fazia"; "culpa e falta de amor próprio"; "fiquei chateada, senti-me angustiada, deu um nó na garganta". Os sentimentos fortes e aversivos em relação à situação de violência do casal protagonista 
mencionados foram: revolta, culpa, pena, dó, tristeza, chateação, angústia, sofrimento, raiva, dentre outros.

A comparação da história da personagem com as histórias das participantes foi muito comum. As semelhanças apontadas foram: "eu dediquei igualzinho a ela e ele também não reconhece"; "culpa e alívio [...] eu também me sentia culpada, mas eu resgatei o meu casamento"; "eu também vivi algumas situações do livro e me identifiquei"; "tive uma tristeza muito grande por mim, como eu deixei tudo isso? Tive uma sensação de leveza ao mesmo tempo, to recomeçando também"; "frustrante em saber que vivi momentos iguais". A identificação vivida pelas mulheres foi acompanhada por sentimentos de culpa, tristeza, frustração e/ou alívio e leveza. A sensação de leveza e alívio foi atribuída por duas participantes pelo fato de enxergar que a vivência de Roz foi mais grave que as delas: "alívio ao saber que não fui paciente e ficar perdendo meu tempo com ele"; "senti uma leveza dentro de mim, vi que o meu problema era leve, não era tão pesado igual ao dela".

Outras participantes perceberam tanta semelhança com a história da personagem que relataram identificação total: "esse livro conta a minha vida"; "como se fosse eu aqui no livro"; "como se estivesse lendo a minha história"; "descobri que este livro conta a minha vida". Várias mulheres transferiram o mal estar sentido com a leitura da história da personagem para o próprio relacionamento conjugal. Alguns relatos revelaram que essa percepção do mal estar foi acompanhada da decisão de adotar estratégias para mudar a história do relacionamento conjugal: "vi que era hora de dar uma virada na minha história". Esse processo pode favorecer a quebra de suas próprias anestesias (Ravazzola, 1997, 1998).

Não houve diferença significativa na reação de identificação com a história entre as mulheres do grupo no início (GSF) e as do final do acompanhamento psicossocial (GSC). Quase todas as participantes citaram vários sentimentos, exceto uma mulher do GSF que descreveu não ter experienciado sentimento algum com a leitura do livro. Esse fato pode indicar uma forte condição de anestesia ou dissociação em relação à violência - naturalizando a violência na relação conjugal (Alves \& Diniz, 2005; Macedo, 2013; Ravazzola, 2007).

Comparação entre as Histórias das Participantes e a História do Livro

A segunda e a terceira perguntas do questionário tiveram o objetivo de compreender semelhanças e diferenças identificadas pelas mulheres entre suas histórias pessoais e a da autora do livro. Apresentaremos os elementos semelhantes para depois apontar as diferenças. 
Todas as participantes relataram ter algo em comum com a vivência da personagem. Elas perceberam como elementos semelhantes: a violência vivenciada por Roz; a infidelidade e mentiras do parceiro; a desresponsabilização do homem; e as consequências da violência.

A leitura do livro pode ajudar as mulheres a nomear a violência vivenciada pela Roz e associá-la a própria vivência. Dentre as 19 participantes, 11 mencionaram o termo "violência" e duas citaram a palavra "agressão". O livro e o questionário podem auxiliá-las a superarem a dificuldade em romper o silêncio e o segredo sobre a violência. Pesquisas já constataram que várias mulheres têm uma tendência a não nomear a violência, o que contribui para a perpetuação das agressões (Diniz \& Pondaag, 2006; Macedo, 2013; Pondaag, 2009).

Uma participante respondeu que "só me veio a ideia que seria eu vivendo tudo aquilo" por ter encontrado muita semelhança com sua história. As participantes revelaram que todos os tipos de violência que ocorreram no livro estavam presentes em suas vidas: "agressão verbal", "violência física", "chamar de burra, idiota", "os xingamentos e palavrões", "tipo de violência verbal, física e mental diárias". Constatamos que as participantes mencionaram muito mais a violência psicológica. Várias pesquisas corroboram essa postura, ao apontarem que as mulheres tendem a considerar a violência psicológica como pior e mais devastadora que as outras formas de violência (Medeiros, 2015; Santos \& Moré, 2011; Zuma, Mendes, Cavalcanti \& Gomes, 2013).

A presença de ciclos de violência (Walker, 1979, 1999) foi muito mencionada: "o ciclo de violência que vai e volta"; "ciclo de amor e ódio"; "os altos e baixos nos sentimentos"; "oscilação do humor". As mulheres também relataram vivenciar a fase de Lua de Mel: "a todo tempo diz que me ama, 'eu não vivo sem você'"; "se fingia de bonzinho"; "no começo me tratava bem"; "pedir desculpas"; "tentar voltar atrás"; "bloqueio das violências". A experiência dessa fase pode produzir nas mulheres falsas expectativas quanto à possibilidade de mudança do companheiro e da relação. Essas expectativas ficam evidentes nos seguintes relatos: "ele dizer que me ama, também perdôo em demasia"; "esperança de que as coisas mudem"; "esperança que ele melhore um dia e seja um companheiro presente".

Esse ciclo ajuda a entender como mulheres em um momento são vitimizadas, e em outro, seduzidas pela expectativa de mudança do parceiro ou da melhoria da relação. Entretanto, a tendência é a fase de Lua de Mel fique cada vez menor e a dar lugar ao predomínio das outras fases (Guimarães et al., 2007; Walker, 1979; Walker et al., 2007). 
Outra semelhança citada pelas participantes foi a vivência de infidelidade e mentiras do parceiro, ilustrada nos seguintes relatos: "ele enganava, traia"; "ele prezar tanto a fidelidade e não retribuir com a mesma fidelidade"; "as mentiras que conta são iguais as da história". Seis mulheres mencionaram o termo "infidelidade"; três associaram o termo à violência: "traição, amor e violência"; "a traição e violência física", "a violência e a traição".

A associação entre violência e infidelidade é corroborada por Souzas e Alvarenga (2001). As autoras defendem que a traição pode ser a porta de entrada para as agressões e atua como mecanismo de afirmação masculina sobre a mulher. Pode ser uma forma de opressão e fortalecer ainda mais a desigualdade de gênero na conjugalidade (Diniz, 2011).

A desresponsabilização do homem e a culpabilização da mulher também foi referida por algumas participantes como semelhante à da história da autora. Esse fato fica evidente nos trechos a seguir: "culpada por não tomar atitude"; "jamais me julgue e se coloque como vítima toda vez que discutimos"; "pensamentos como culpa do álcool"; "pena, dó de denunciar e prejudicá-lo"; "se fazer de coitado"; "tomei-me como culpada e promotora dos episódios"; "perdôo em demasia"; "meu modo compassivo de ser".

A desresponsabilização do homem e a culpabilização da mulher pelo abuso contribuem para a perpetuação da dinâmica conjugal violenta. Homens e mulheres tendem a justificar a violência e a atribuir os atos violentos a fatores externos ao parceiro e à relação: álcool, doenças, estresse, transtornos psiquiátricos, dentre outros. As mulheres podem negar a violência sofrida e sentir-se obrigadas a ficar na relação para cuidar do cônjuge. A adesão rígida a papéis e estereótipos de gênero contribui com que mulheres aceitem a vitimização e a culpabilização impostas pelo parceiro, por si próprias e pela sociedade (Cunha, 2008; Hamilton et al., 2013; Lima \& Büchele, 2011; Medeiros, 2010, 2015; Schmidt, 2010).

A maioria das participantes identificou semelhanças entre consequências das violências vividas por Roz e por elas. Esse processo ficou evidente nas seguintes falas: "isso acaba com qualquer mulher, já passei por isso sei que é muito doloroso", "deixar a vida de lado e viver em função do marido"; "vergonha de tá no meio dos outros"; "muita insegurança, promoção de isolamento, contra o qual ainda encontro-me em estado de alerta"; "cheguei a ficar muito assustada"; "perdi minha identidade dentro da situação de conflito"; e "o envolvimento das crianças". As mulheres enfatizaram as consequências psicológicas e sociais. Nenhuma citou as marcas corporais. A violência dói no corpo, mas parece afetar muito mais a saúde mental das participantes (Diniz, 2011; Medeiros, 2010, 2015; Santos \& Moré, 2011). 
As participantes também reconheceram a diminuição da rede social e familiar como consequência da violência (Diniz, 2011; Moore, 2015). $\mathrm{O}$ isolamento constitui fator de risco e também efeito da violência, que gera um ciclo vicioso e favorece a perpetuação da dinâmica.

As participantes do grupo GSC, provavelmente por estarem finalizando o acompanhamento psicossocial, se mostraram mais conscientes do impacto da violência conjugal em suas vidas. A leitura do livro associada à reflexão e ao processo de intervenção em grupo tem o potencial de promover uma ressignificação das experiências conjugais por meio da identificação de elementos semelhantes de suas histórias com a da personagem.

\section{Elementos Diferentes}

A análise de conteúdo quanto aos elementos diferentes listados pelas participantes originou duas categorias. As diferenças foram relacionadas à gravidade da dinâmica violenta: 1) a vivência de violência de Roz foi pior que a delas ou 2) histórias das participantes tiveram algo pior do que a de Roz.

Diversas participantes apontaram que a vivência de violência de Roz foi pior que a delas em pelo menos algum aspecto. Algumas ressaltaram que no relacionamento delas "não teve traição", "nunca houve envolvimento com outras mulheres"; outra apontou a importância da formalização - "o casamento foi na igreja" e Roz nunca se casou; e outra a duração da relação - "casamento dela (Roz) foi curto". Várias mencionaram o tipo de agressão - "não teve violência sexual", "agressões são mais verbais" enquanto na relação de Roz aconteceram diversas formas de violência; e também o fato de terem tomado consciência das dificuldades e terem deixado a relação mais rápido: "apesar de eu amar, esse amor não é sustentáculo para continuidade de um ciclo"; "eu enxerguei o que realmente estava acontecendo, não quis me iludir e nem me enganar mais"; "nunca me iludi que ele mudaria"; "os problemas são recentes"; "nunca me obrigou a nada".

Algumas apontaram como diferença positiva o fato de as ações violentas não terem sido direcionadas aos filhos - "nunca percebi que meus filhos tenham sofrido abuso sexual praticado pelo pai"; "os xingamentos não existem com os filhos, ele é um pai neutro"; ou estarem circunscritas a um contexto - "só fica agressivo quando bebe".

Essas participantes consideraram o relacionamento conjugal de Roz mais trágico que o relacionamento delas. Valorizaram o fato de seus casamentos serem oficializados na igreja e a vivência da maternidade, situação diferente da história da personagem do livro. Cunha (2008) afirma que o status de estar casada é muito valorizado na sociedade patriarcal enquanto estar separada ou viver em união 
estável ainda significa depreciação da mulher. Essa depreciação também ocorre em relação às mulheres que não têm filho - elas ainda são vistas como fracassadas por não cumprirem as expectativas sociais relacionadas à maternidade.

Algumas participantes também revelaram que suas histórias tiveram algo pior do que a de Roz. Os seguintes trechos exemplificam esses relatos: "eu sempre fui triste, porque nunca fui feliz, sempre me magoei"; "o meu marido não bebe, não é nada romântico, depois de casado nunca falou que me ama"; "ela não ficou presa a religião como eu fico", "falta de apoio da família", "falta de amor próprio", "somente a bebida, ele não bebia", "tinha espancamento constante", "crianças ficaram contra mim".

A percepção de que o parceiro agride sem que a mulher possa colocar a culpa no álcool mostrou ser algo extremamente frustrante. Nesse contexto ela não tem a possibilidade de desresponsabilizar o homem autor. Esse fato reforça dados da literatura que apontam que não existe uma relação causal entre bebida e violência (Schmidt, 2010; Walker, 1979, 1999).

Algumas participantes também enxergarem sua relação como pior do que a da Roz pela ausência da fase de Lua de Mel do ciclo de violência (Walker, 1999). A constatação de que o parceiro não é romântico, nunca diz que a ama e que ocorre espancamento constantemente mostra que na relação prevalece apenas as fases de Aumento da Tensão ou de Tensão Máxima. Essa conscientização é geradora de angústia, mas também carrega o potencial de criar a possibilidade da mulher se empoderar para se libertar (Pondaag, 2009).

A religião e a falta de apoio familiar foram relacionadas como fatores que podem piorar uma relação conjugal violenta. O afastamento da rede já foi discutido anteriormente. A religião foi mencionada como fator protetivo e como fator de risco. No primeiro caso, a mulher só encontrou apoio e conforto em sua crença religiosa, pois não "tinha amor próprio" e nem familiares para ajudá-la. Na segunda situação, a participante enxergou a religião como uma verdadeira prisão, pois se sentia obrigada a permanecer na relação violenta a qualquer custo. Nesse caso, a religião atua como fator anestesiante ao contribuir para que a mulher tolere a manutenção ou a escalada das agressões (Walker, 1979, 1999; Walker et al., 2007).

Reflexão sobre as Anestesias Relacionais

O objetivo das perguntas quatro, cinco e seis do questionário foi identificar as anestesias relacionais que favoreceram a permanência das mulheres em um relacionamento violento e/ou geraram dificuldade em pedir ajuda a terceiros ou às instituições. Na quarta pergunta as participantes puderam escolher as anestesias listadas 
pela Roz que elas identificaram como presentes em suas próprias histórias. A pergunta cinco pedia às participantes para escolhessem três dentre as 35 anestesias que elas perceberam como as anestesias mais importantes na sua vivência da relação violenta.

Todas as 35 anestesias listadas foram marcadas pelo menos uma vez. Sete anestesias foram marcadas por mais da metade das mulheres, indicando um alto reconhecimento de sua influência na manutenção da relação: "Talvez ele melhore...", "Onde foi que eu errei?", "Talvez eu deva falar menos...", "Ele jura que não vai acontecer de novo...", "Eu não deveria perdoar?", "Quem disse que a vida é fácil?" e "Não é uma pessoa má".

A quantidade de anestesias marcadas por cada mulher variou de 3 a 25 dentre as 35 opções listadas pela autora do livro. Algumas mulheres tiveram alta identificação com os pensamentos, sentimentos e ações da personagem. A média foi de 11,73 anestesias por mulher, sendo 13,20 do GSC e 10,11 do GSF. As participantes que estão no final da intervenção em grupo marcaram mais anestesias. Na quinta pergunta, todas as participantes escolheram e escreveram três anestesias no campo apropriado do questionário. Uma mulher listou quatro anestesias.

\section{Anestesias Relacionais Listadas pelas Próprias Participantes}

O objetivo da pergunta seis do questionário foi averiguar as anestesias que as participantes consideravam importantes a partir de suas próprias histórias. Cabia a elas também acrescentar anestesias advindas de sua experiência e que não estavam listadas no estímulo fornecido. Caso as mulheres respondessem que "sim", o questionário dava a elas a opção de preencher até três campos com as suas próprias anestesias.

Oito mulheres citaram três anestesias. Seis não acrescentaram nenhuma. As demais apontaram uma ou duas anestesias diferentes da personagem. As participantes do GSC descreveram mais anestesias que as do GSF. Esse dado, aliado às respostas dadas à pergunta anterior, indica que mulheres ao fim do acompanhamento psicossocial podem estar mais conscientes das anestesias que favorecem a sua permanência na relação conjugal violenta.

Além da questão numérica, é importante analisar o significado das anestesias. Realizamos uma categorização que nos permitiu agregar as anestesias indicadas no livro que as participantes consideraram mais influentes e as próprias anestesias nomeadas sem estímulos. Constatamos a existência de cinco categorias de anestesias que têm mais impacto sobre a vivência da violência das participantes dessa pesquisa. São elas: "consequências da separação e da denúncia", "expectativa de mudança", "ambiguidade e minimização do próprio sentimento", "culpabilização da mulher" e "desresponsabilização do 
ex/parceiro". Essas categorias serão apresentadas e detalhadas qualitativamente em artigo específico.

Nomeação da Vivência de Violência a Partir do Título do Livro

As duas últimas perguntas do questionário tiveram o objetivo de conhecer como as participantes nomearam e perceberam a própria história tendo como estímulo o título do livro "Mas ele diz que me ama" (Penfold, 2006). A pergunta apresentada no questionário para que as mulheres nomeassem a sua vivência foi a seguinte: "A Roz resumiu a história dela com o título: 'Mas ele diz que me ama...'. Qual seria o título da sua história?".

Título das Próprias Histórias pelas Participantes

Constatamos algumas características em comum nos títulos apresentados pelas mulheres. Os elementos que fizeram parte de títulos pensados pelas participantes geraram as seguintes categorias: 1) A ambiguidade de sentimentos; 2) A percepção da realidade violenta na relação; e 3) A expectativa de uma nova vida após a separação.

Diversos títulos indicaram a ambiguidade de sentimentos presentes no relacionamento conjugal. $O$ paradoxo entre amor e violência contribuiu para que algumas participantes ficassem totalmente confusas sobre o vínculo com o parceiro (Angelim, 2009; Angelim \& Diniz, 2010). Essa característica foi apresentada por mulheres dos dois grupos, de acordo com os seguintes trechos: "teu silêncio e tua frieza me deixam em dúvidas do que sentes por mim"; "o homem que diz me amar me dirigiu a palavra nesses termos..."; "apesar dos pesares, eu o amo tanto!"; "mas suas atitudes não condizem"; "amor e ódio"; "por que se chama de amor se traz tantas dúvidas, medos e inseguranças. Será mesmo amor?".

A ambiguidade favorece a reafirmação do relacionamento e gera a impressão de que o casal tem que continuar junto de qualquer forma, mesmo com a violência. Os seguintes trechos reafirmam essa percepção: "você é a mulher da minha vida"; "mas ele diz que não consigo viver sem você". Esses paradoxos do afeto revelam que o homem que agride sua parceira não é violento o tempo todo, como preconiza o mito social (Walker, 1999). A relação também engloba uma dimensão de afeto positivo. Algumas mulheres podem ficar confusas quanto a continuar ou não com o parceiro que às vezes é bom, e às vezes a agride. Ademais, a relação dos cônjuges vai muito além da violência - existe afeto, agressão, amor, ódio, respeito, desprezo, confiança, medo, etc. (Ferreira, Moura, Morgado \& Gryner, Castello Branco, 2013). 
Outra característica que se destaca nos títulos apresentados pelas participantes é a percepção da realidade violenta da relação, de que algo não vai bem com o parceiro, com ela ou com o casal. Essa característica também esteve presente nos dois grupos de mulheres, apesar de ter maior incidência no GSC, evidenciada em quatro citações: "o desprezo de um homem", "eu nunca fui feliz com ele", "a decepção de uma sonhadora", "eu não conhecia o amor próprio". No grupo GSF teve duas ocorrências desse tipo de constatação: "a insistência dele foi em vão", "ele não me ama".

Três mulheres do GSF apresentaram títulos opostos à constatação da realidade violenta, justamente por ter a expectativa de mudança do parceiro ou de melhoria da relação. Ao nomear a história como "dême mais uma chance, a última", "Deus é fiel! Eu creio muito, tenho fé em Deus, que vai melhorar ainda, eu te garanto" e "ele merece uma chance para mudar" as mulheres estão apostando no fim da violência.

A expectativa de poder construir uma nova vida foi apresentada por duas participantes, uma de cada grupo. Ao escolherem como títulos "Saindo do cativeiro" e "Um dia serei feliz" elas afirmam o desejo de continuar suas vidas sem a violência. A primeira está separada do parceiro e espera reconstruir a sua história sem ele. A segunda continua com o cônjuge, o que pode significar a esperança de mudança dentro da relação ou com o rompimento do vínculo.

Percepção da própria história a partir do título do livro

A pergunta oito do instrumento teve o seguinte comando: "Inspirada em sua história, complete a frase/título do livro: "Mas ele diz que me ama...". O intuito foi de, mais uma vez, facilitar a nomeação e a percepção da conjugalidade como violenta.

A continuidade do título do livro criada pelas participantes mostrou que todas as mulheres começaram a ter consciência de que há algo errado em sua relação conjugal. Os conteúdos revelaram que elas questionaram o paradoxo entre o amor que o parceiro afirma sentir e a violência que ele pratica. O exercício de dar continuidade ao título deixou claro que elas se posicionaram contra a existência dessa contradição.

Além das denúncias dos paradoxos do amor, algumas participantes foram capazes de assumir a inexistência de afeto. No GSC, três mulheres afirmaram que não existe amor na relação: "ele nunca me diz que me ama, nunca falou"; "ele não ama nem a si mesmo"; e "eu continuo dizendo que ele não ama". Uma participante afirma não depender do sentimento dele para reconstruir a sua vida - ela já se encontra separada do parceiro e mostrou estar no caminho de resgatar a sua autoestima: "não quero nem saber, eu vou me amar mais". 
Uma participante do GSF afirmou, ao criar a continuidade do título do livro, o extremo paradoxo entre amor e violência: "Mas ele diz que me ama... mas ele quer me matar". Ela indica claramente ter consciência da possibilidade do relacionamento conjugal chegar a um fim trágico: a morte de um dos cônjuges, provavelmente a dela - o que reafirma a tendência a ocorrer uma escalada da violência com o desfecho de feminicídio (Medeiros, 2015; Teixeira, 2009; Waiselfisz, 2012; Yamamoto \& Colares, 2015).

As respostas às duas últimas questões do instrumento - que envolveu criar um título para a sua própria história e completar o título criado pela personagem - serviram como indicadores de que intervenção permitiu às participantes iniciar o processo de nomeação e percepção de suas próprias histórias como violentas e as contradições da relação violenta.

A análise conjunta da resposta de uma mesma participante às perguntas sete e oito do questionário possibilita uma reflexão sobre o paradoxo entre as anestesias apresentadas pelas mulheres e a percepção da realidade violenta da conjugalidade. Esse paradoxo contribui para a instalação de padrão duplo-vincular na conjugalidade violenta (Angelim, 2009; Angelim \& Diniz, 2010). A compreensão dos critérios de duplo-vínculo em casos de violência conjugal será apresentada e detalhada em artigo específico.

\section{Considerações Finais: Saindo do Cativeiro para um Dia Ser Feliz}

A estratégia metodológica utilizada nesta pesquisa-intervenção criou um contexto adequado para reflexão sobre a dinâmica conjugal violenta. O sentimento despertado, a partir da leitura do livro, e a identificação com a história da personagem, ofereceram uma oportunidade para as mulheres refletirem sobre suas próprias histórias; estimularam a comparação entre as histórias pessoais e a de Roz; favoreceram a percepção e reflexão sobre as próprias anestesias; e contribuíram para a nomeação e percepção da violência vivida.

Várias participantes voltaram ou começaram a enxergar a injustiça cometida pelos parceiros e os perigos da violência para sua integridade física e mental, processo importante para "desanestesiálas" e ajudá-las a reconhecer e nomear a violência sofrida. Algumas delas puderam perceber que tem capacidade e recursos para se proteger. Algumas relataram não sentir mais vergonha no lugar do parceiro - passaram a ver que ele é o responsável pela agressão. Constatamos que a reativação dos sentimentos que estavam adormecidos pode ser fundamental para as mulheres começarem a 
reagir novamente à violência. Essa reação constitui outro passo importante no sentido de interromper a violência e sair do cativeiro.

A estratégia de pesquisa e intervenção proposta aqui pode ser um método importante de identificação de dinâmicas relacionais presentes nas conjugalidades violentas: mitos, anestesias e o ciclo de violência. Todos esses processos são marcados por construções de gênero. Essas dinâmicas puderam ser identificadas por meio dos relatos das mulheres participantes, ao refletirem sobre a leitura do livro e as respostas ao questionário.

$\mathrm{Na}$ maioria das vezes são os profissionais que reconhecem essas dinâmicas e apontam sua ocorrência. Algumas mulheres nem sempre estão preparadas para ouvi-las, mesmo após a denúncia da violência. Esse processo pode levar muito tempo e mesmo assim não ser eficaz em promover o reconhecimento dessa dinâmica por parte da mulher. O fato de o livro ter sido escrito no formato de uma história em quadrinhos aliado à utilização do questionário e à reflexão grupal estimulou a identificação e nomeação das dinâmicas pela própria mulher. Facilitar essa identificação pela própria mulher vítima é o grande diferencial dessa pesquisa. A possibilidade de autorreflexão e nomeação tem um valor clínico inestimável - potencializa o processo de ruptura com crenças, valores e ideias internalizadas que mantêm a mulher no cativeiro emocional, relacional e social.

A estratégia proposta mostrou seu potencial e utilidade como método de pesquisa e como meio de intervenção. Esperamos, portanto, que esse estudo contribua para que outros(as) profissionais e pesquisadores(as) se interessem pela utilização dessa estratégia.

Esperamos que a utilização e o aprimoramento dessa proposta de pesquisa e intervenção possam ajudar outras mulheres a literalmente saírem do cativeiro e terem esperança de um dia realmente serem muito felizes. Acreditamos que a leitura do livro, o preenchimento do questionário e a reflexão em grupo, somados, têm o potencial de empoderar mulheres. Tal empoderamento é fundamental para elas não se deixarem levar cegamente pelas falas-armadilhas dos parceiros - "mas eu te amo..." - e por suas próprias falasarmadilhas: "mas ele diz que me ama...". Ao se tornarem capazes de ouvir e levar a sério o que o coração sente e o que a percepção capta sobre a realidade trágica do relacionamento conjugal elas podem assumir mudar suas próprias vidas.

\section{Referências}

Alves, S. L. B., \& Diniz, N. M. F. (2005). Eu digo não, ela diz sim: a violência conjugal no discurso masculino. Revista Brasileira de Enfermagem, 58(4), 387-392. 
Angelim, F. P. (2009). Mulheres vítimas de violência: dilemas entre a busca da intervenção do Estado e a tomada de consciência (Tese de Doutorado). Universidade de Brasília, Brasília, DF, Brasil.

Angelim, F. P., \& Diniz, G. R. S. (2010). A Teoria do Duplo-Vínculo como referencial teórico para intervenções em casos de violência contra mulheres. In I. Ghesti-Galvão \& E. C. B Roque (Orgs.). Aplicação da lei em uma perspectiva interprofissional: Direito, psicologia, psiquiatria, serviço social e ciências sociais na prática jurisdicional (pp. 397-412). Brasília: Editora Lumen Juris.

Cunha, T. R. A. (2008). Violência conjugal: os ricos também batem. Publicatio UEPG, Ponta Grossa, 16(1), 167-176.

Diniz, G. R. S. (2011). Conjugalidade e violência: reflexões sob uma ótica de gênero. In Terezinha Féres-Carneiro (org.), Casal e família: conjugalidade, parentalidade e psicoterapia, (pp. 1126). São Paulo: Casa do Psicólogo.

Diniz, G. R. S., \& Pondaag, M. C. M. (2006). A face oculta da violência contra a mulher: o silêncio como estratégia de sobrevivência. In A. M. O. Almeida, M. F. S. Santos, G. R. S. Diniz \& Z. A. Trindade (Orgs.). Violência, Exclusão Social e Desenvolvimento Humano: Estudos em Representações Sociais (pp. 233-259). Brasília: Editora Universidade de Brasília - Ed. UnB.

Ferreira, A. L., Moura, A. T. M. S., Morgado, R., Gryner, S., Castello Branco, V. M. (2013) Crianças e adolescentes em situação de violência. In K. Njaine, S. G. de Assis \& P. Constantino, Impactos da Violência na Saúde (pp. 127-148) (3a ed.). Rio de Janeiro: Fundação Oswaldo Cruz.

Guimarães, F., Silva, E. C., \& Maciel, S. A. B. (2007). “Mas ele diz que me ama...": Cegueira relacional e violência conjugal. Psicologia: Teoria e Pesquisa, 23(4), 481-482.

Hamilton, L., Koehler, J. A., Lösel, F. A. (2013) Domestic Violence Perpetrator Programs in Europe, Part I: A survey of Current Practice. International Journal of Offender Therapy and Comparative Criminology, 57(10), 1189-1205.

Lima, D. C., \& Büchele, F. (2011). Revisão crítica sobre o atendimento a homens autores de violência doméstica e familiar contra as mulheres. Physis: Revista de Saúde Coletiva, 21(2), 721-743.

Macedo, D. S. (2013). Exercícios para Liberação da Tensão e do Trauma (TRE): aplicação a situações de violência conjugal (Dissertação de Mestrado). Instituto de Psicologia, Universidade de Brasília, Brasília.

Medeiros, M. N. (2010). Violência conjugal: repercussões na saúde mental de mulheres e de suas filhas e seus filhos adultas/os 
jovens (Dissertação de Mestrado). Universidade de Brasília, Brasília, DF, Brasil.

Medeiros, M. N. (2015). Avaliação de risco em casos de violência perpetrada por parceiro íntimo: a identificação da reincidência e da letalidade (Tese de Doutorado). Universidade de Brasília, Brasília, DF, Brasil.

Moore, R. A. (2015). Violência e gênero: vulnerabilidade masculina (Dissertação de Mestrado). Instituto de Psicologia, Universidade de Brasília, Brasília, Brasil.

Penfold, R. B. (2006). Mas ele diz que me ama: graphic novel de uma relação violenta. (D. Pelizzari, trad.). Rio de Janeiro: Ediouro. (Trabalho original publicado em 2005).

Pondaag, M. C. M. (2009). Sentidos da Violência Conjugal: a perspectiva de casais (Tese de Doutorado). Universidade de Brasília, Brasília, DF, Brasil.

Ravazzola, M. C. (1997). Historias infames: los maltratos en las relaciones. Buenos Aires: Paidós.

Ravazzola, M. C. (1998). Violencia familiar: el abuso relacional como un ataque a los derechos humanos. Sistemas Familiares, 4(3), 29-41.

Ravazzola, M. C. (2007). Violência nas Relações Familiares: Por que uma visão sistêmica e de gênero? Pensando Famílias, 11(1), $11-28$.

Santos, A. C. W., \& Moré, C. L. O. O. (2011). Repercussão da violência na mulher e suas formas de enfrentamento. Paidéia, 21(49), 227-235.

Schmidt, B. B. L. B. (2010). Ciclos de violência e alcoolismo na conjugalidade: construções subjetivas dos homens agressores e alcoolistas (Dissertação de mestrado). Instituto de Psicologia, Universidade de Brasília, Brasília, Brasil.

Seidl de Moura, M. L. \& Ferreira, M. C. (2005). Projetos de Pesquisa: Elaboração, redação e apresentação. Rio de Janeiro, RJ: EDUERJ .

Souzas, R. \& Alvarenga, A. T. (2001). Da negociação às estratégias: relações conjugais e de gênero no discurso de mulheres de baixa renda em São Paulo. Saúde e Sociedade, 10(2), 15-31.

Teixeira, A. B. (2009). Nunca você sem mim: homicidas-suicidas nas relações afetivo-conjugais. São Paulo: Annablume.

Waiselfisz, J. J. (2012). Mapa da Violência 2012. Os novos padrões da violência homicida no Brasil - Caderno Complementar 1: Homicídios de Mulheres no Brasil. São Paulo: Instituto Sangari.

Walker, L. E. (1979). The battered woman. Nova York: Harper Perennial.

Walker, L. E. A. (1999). The battered woman syndrome. (2o ed.). Nova York: Springer Publishing Company. 
Walker, L. E., Duros, R. I., \& Tome, A. (2007). The battered woman syndrome. Nova York: Springer Publishing Company.

Yamamoto, A., \& Colares, E. S. (2015). Por que falar em feminicídio? Observa Gênero, 47(7), 5-7.

Zuma, C. E, Mendes, C. H. F., Cavalcanti, L. F., \& Gomes, R. (2013). Violência de gênero na vida adulta. In K. Njaine, S. G. de Assis \& P. Constantino (Orgs.), I mpactos da Violência na Saúde (pp. 149-186) (3a ed.). Rio de Janeiro: Fundação Oswaldo Cruz.

\author{
Endereço para correspondência \\ Fabrício Lemos Guimarães \\ Universidade de Brasília - UnB \\ Rua das Águas, q. 8 lote 17, São Caetano, CEP 72805-140, Luziânia - GO, Brasil \\ Endereço eletrônico: billguimaraes@yahoo.com.br \\ Gláucia Ribeiro Starling Diniz \\ Universidade de Brasília - UnB \\ Programa de Pós-graduação em Psicologia Clínica e Cultura \\ UnB Colina, bloco H apto 106, Asa Norte, CEP 70904-108, Brasília - DF, Brasil \\ Endereço eletrônico: gdiniz@unb.br
}

Recebido em: 28/08/2015

Aceito em: 18/06/2017

Notas
* Doutor e Mestre em Psicologia Clínica e Cultura.
** PhD.

Este artigo de revista Estudos e Pesquisas em Psicologia é licenciado sob uma Licença Creative Commons Atribuição-Não Comercial 3.0 Não Adaptada. 